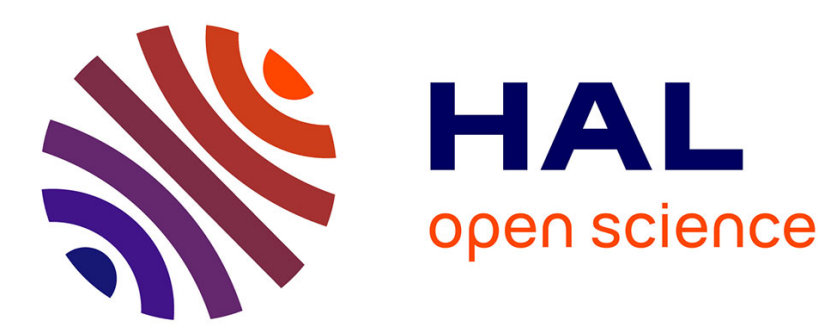

\title{
High-Field Magnetization Behavior of Mn-Al-C Alloys
}

A Pasko, F Mazaleyrat, L. K. Varga, P Stamenov, J.M.D. Coey

\section{To cite this version:}

A Pasko, F Mazaleyrat, L. K. Varga, P Stamenov, J.M.D. Coey. High-Field Magnetization Behavior of Mn-Al-C Alloys. IEEE Transactions on Magnetics, 2014, 50, pp.1 - 4. 10.1109/TMAG.2014.2320598 . hal-01100219

\section{HAL Id: hal-01100219 \\ https://hal.science/hal-01100219}

Submitted on 22 Jan 2015

HAL is a multi-disciplinary open access archive for the deposit and dissemination of scientific research documents, whether they are published or not. The documents may come from teaching and research institutions in France or abroad, or from public or private research centers.
L'archive ouverte pluridisciplinaire HAL, est destinée au dépôt et à la diffusion de documents scientifiques de niveau recherche, publiés ou non, émanant des établissements d'enseignement et de recherche français ou étrangers, des laboratoires publics ou privés. 


\title{
High-field magnetization behavior of Mn-Al-C alloys
}

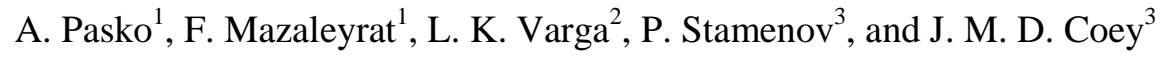 \\ ${ }^{1}$ SATIE, ENS Cachan, CNRS, UniverSud Paris, 94235 Cachan, France \\ ${ }^{2}$ ISSPO, Wigner RCP, HAS, Budapest 1525, POB 49, Hungary \\ ${ }^{3}$ School of Physics and CRANN, Trinity College, Dublin 2, Ireland
}

\begin{abstract}
Dense Mn-Al-C permanent magnets have been produced using melt-spinning and spark plasma sintering techniques. The samples have been magnetically characterized from $4 \mathrm{~K}$ to $300 \mathrm{~K}$ in a field of up to $14 \mathrm{~T}$. The ahysteretic parts of magnetization loops were analyzed within a model for the approach to saturation which allows for possible crystallographic texture. The saturation magnetization and magnetocrystalline anisotropy energy have been determined taking into account the estimated fraction of ferromagnetic phase. The obtained magnetic parameters have been compared with available theoretical and experimental data.
\end{abstract}

Index Terms - Magnetic anisotropy, manganese-aluminum alloys, permanent magnets, spark plasma sintering.

\section{INTRODUCTION}

Recent years have seen a renewed interest in the Mn-Al alloys, first reported by Kono [1] and Koch et al. [2], as promising candidates for permanent magnet applications. These materials belong to the large family of ferromagnetic phases with $\mathrm{L}_{0}$ ordered structure and possess a high uniaxial magnetocrystalline anisotropy arising from a breakdown of the cubic crystal symmetry to a tetragonal one. The escalating prices of rare earths present an industrial opportunity for new rare-earth-free magnets such as the $\mathrm{Mn}$-Al-based alloys having good technological properties (light, strong, machinable) and low cost. With proper optimization, they would be capable of filling the gap between cheap hexagonal ferrites and highperformance Nd-Fe-B magnets [3]-[5]. The ferromagnetic tetragonal $\tau$-phase is metastable and can be obtained in the $\mathrm{Mn}_{0.5+x} \mathrm{Al}_{0.5-x}$ alloy $(x=0-0.1)$ alloy by quenching the hightemperature hexagonal $\varepsilon$-phase with subsequent annealing at 673-973 K. In order to stabilize the ferromagnetic phase, carbon has been introduced into the crystal lattice, which also improves coercivity due to fine $\mathrm{Mn}_{3} \mathrm{AlC}$ precipitates [6]. The mechanism of phase formation comprises either an atomic ordering followed by a martensitic (diffusionless) phase transition or a massive (thermally activated compositioninvariant) structural transformation [7]. The magnetic hysteresis of $\mathrm{Mn}-\mathrm{Al}-\mathrm{C}$ alloys is therefore sensitive to the microstructure and lattice defects developed during the $\tau$ phase formation and is greatly influenced by the manufacturing route.

Textured Mn-Al-C samples with optimized functional properties were produced in Japan by hot extrusion [6]. Various methods have been proposed to make isotropic magnets: melt-spinning [8]-[11], gas atomization [11]-[13], mechanical alloying [14]. In addition, a ball milling step was introduced after quenching [15] or rapid solidification [11], [13] for experiments with nanostructured materials. Despite relatively high magnetocrystalline anisotropy, it has not been easy to develop coercivity in the Mn-Al-C alloys. In this paper we report on the high-field magnetic characterization of the

Manuscript received March 7, 2014. Corresponding author: A. Pasko (email: pasko@ satie.ens-cachan.fr).

Digital Object Identifier inserted by IEEE
Mn-Al-C bulk samples produced by spark plasma sintering (SPS). The idea behind SPS is simultaneous application of heat and pressure for more efficient consolidation of powders. Unlike hot pressing, SPS uses a resistive heating by a pulsed electric current passing directly through the sample [16]. When applied to the synthesis of dense Mn-Al-C magnets, this technique can be advantageous, by combining in one step the heat treatment necessary for the $\tau$-phase formation and the powder sintering itself, while avoiding excessive grain coarsening and decomposition of the metastable phases. Magnetic measurements in a high-field region enable us to determine the saturation magnetization and magnetocrystalline anisotropy energy, within a model for the approach to saturation.

\section{EXPERIMENTAL}

Ternary $\mathrm{Mn}_{54} \mathrm{Al}_{44} \mathrm{C}_{2}$ and $\mathrm{Mn}_{49} \mathrm{Al}_{49} \mathrm{C}_{2}$ alloys were prepared from pure elements by induction melting in a water-cooled copper crucible. The ingots were then cast into $\sim 3 \mathrm{~mm}$ wide and $\sim 25 \mu \mathrm{m}$ thick ribbons using the melt-spinning technique under protective atmosphere at a wheel speed of $25 \mathrm{~m} \cdot \mathrm{s}^{-1}$ [9]. The ribbons appeared brittle and were subsequently ground by hand with pestle and mortar. The obtained powders were compacted in a graphite die with internal diameter of $8 \mathrm{~mm}$ and sintered in a Sumitomo Dr. Sinter Lab SPS machine under vacuum with an applied uniaxial pressure of $70 \mathrm{MPa}$. Two thermal regimes were chosen with a maximum temperature of $923 \mathrm{~K}$ or $1223 \mathrm{~K}$, heating/cooling rate of $6000 \mathrm{~K} \cdot \mathrm{s}^{-1}$ and a dwell time of $300 \mathrm{~s}$. At lower temperatures sintering is accompanied by the $\varepsilon \rightarrow \tau$ phase transition; at higher temperatures the material is sintered in the stable $\varepsilon$-phase state, and transformation to the $\tau$-phase occurs on cooling [17]. Crystal structures were determined by a PANalytical X'Pert Pro X-ray diffractometer (XRD) equipped with an X'Celerator detector. Magnetic measurements were carried out using a Quantum Design PPMS instrument in a temperature range of 4-300 K and in an applied field of up to $14 \mathrm{~T}$.

\section{RESULTS}

According to the phase diagram of the Mn-Al system [18], two equilibrium paramagnetic phases can be formed in the 
compositional range concerned: the Mn-rich cubic $\beta$-phase and the Al-rich trigonal $\gamma_{2}$-phase. In addition, two metastable phases may appear in non-equilibrium conditions: disordered hexagonal $\varepsilon$-phase and ordered tetragonal $\tau$-phase. Stable at higher temperatures, the paramagnetic $\varepsilon$-phase can be preserved on quenching and converted into the ferromagnetic $\tau$-phase by a composition-invariant structural transformation. The resulting phase constitution and related magnetic properties are therefore strongly dependent on the heat treatment regime.

\section{FIG. 1 HERE}

Magnetic hysteresis loops of the $\mathrm{Mn}_{49} \mathrm{Al}_{49} \mathrm{C}_{2}$ and $\mathrm{Mn}_{54} \mathrm{Al}_{44} \mathrm{C}_{2}$ alloys, sintered at $923 \mathrm{~K}$ or $1223 \mathrm{~K}$, at room temperature in a field of up to $5 \mathrm{~T}$ are compared in Fig. 1. In the $\mathrm{Mn}-\mathrm{Al}$ system an excess of $\mathrm{Mn}$ is usually required to stabilize the ferromagnetic $\tau$-phase. Hence, the $\mathrm{Mn}_{54} \mathrm{Al}_{44} \mathrm{C}_{2}$ samples show higher magnetization, in spite of partial occupation of $\mathrm{Al}$ sites by $\mathrm{Mn}$ atoms with antiferromagnetic $\mathrm{Mn}-\mathrm{Mn}$ coupling. However, the $\mathrm{Mn}_{49} \mathrm{Al}_{49} \mathrm{C}_{2}$ samples have higher coercivity due to the presence of a parasitic phase. The increase of sintering temperature leads to denser material with higher content of the $\tau$-phase, but adversely affects its coercivity. The XRD phase analysis confirms the correlation between the $\tau$-phase mass fraction and the saturation magnetization value.

\section{FIG. 2 HERE}

In view of its better combination of magnetic properties, the $\mathrm{Mn}_{54} \mathrm{Al}_{44} \mathrm{C}_{2}$ alloy, sintered at $923 \mathrm{~K}$, was selected for further detailed high-field characterization. Fig. 2 shows the magnetization as a function of temperature, measured in a constant field of $14 \mathrm{~T}$, together with a quadratic in $T$ fitting curve. The specific moment extrapolated to $0 \mathrm{~K}$ is $\sigma_{\mathrm{s}}=114 \mathrm{~A} \cdot \mathrm{m}^{2} \cdot \mathrm{kg}^{-1}$. According to the comparative analysis of structural and magnetization data, this sample contains approximately $85 \%$ of the ferromagnetic phase [17]. Taking into account the $\tau$-phase density $5086 \mathrm{~kg} \cdot \mathrm{m}^{-3}$, we can estimate the equivalent single-phase saturation magnetization as $M_{\mathrm{s}}=0.68 \mathrm{MA} \cdot \mathrm{m}^{-1}\left(\mu_{0} M_{\mathrm{s}}=0.86 \mathrm{~T}\right)$.

\section{FIG. 3 HERE}

Magnetic hysteresis loops of this alloy in a field of up to $14 \mathrm{~T}$ at $4 \mathrm{~K}$ and $300 \mathrm{~K}$ are presented in Fig. 3. The large reversible segments of these curves have been analyzed using a model describing the approach to saturation in textured materials. The total magnetic moment as a function of applied field is calculated by averaging the numerical solution of the torque equation over possible orientations of anisotropy axes. The orientation distribution is described by a simple expression with minimum number of free parameters. The resulting model function is used to fit directly, using nonlinear least-squares regression, the experimental data.

\section{FIG. 4 HERE}

Fitting of the ahysteretic part of magnetization loops for the $\mathrm{Mn}_{54} \mathrm{Al}_{44} \mathrm{C}_{2}$ alloy, sintered at $923 \mathrm{~K}$, is shown in Fig. 4. The approach to saturation at $300 \mathrm{~K}$ corresponds well to isotropic material. However, the magnetization curve at $4 \mathrm{~K}$ can be better fitted with an assumption of anisotropic texture. The specific moment is $\sigma_{\mathrm{s}}=114 \mathrm{~A} \cdot \mathrm{m}^{2} \cdot \mathrm{kg}^{-1}$ at $4 \mathrm{~K}$ and $\sigma_{\mathrm{s}}=98 \mathrm{~A} \cdot \mathrm{m}^{2} \cdot \mathrm{kg}^{-1}$ at $300 \mathrm{~K}$; the anisotropy field is $H_{\mathrm{a}}=4.0 \mathrm{MA} \cdot \mathrm{m}^{-1}\left(\mu_{0} H_{\mathrm{a}}=5.0 \mathrm{~T}\right)$ at $4 \mathrm{~K}$ and $H_{\mathrm{a}}=3.1 \mathrm{MA} \cdot \mathrm{m}^{-1}$ $\left(\mu_{0} H_{\mathrm{a}}=3.9 \mathrm{~T}\right)$ at $300 \mathrm{~K}$. Using again the estimated mass fraction of the $\tau$-phase, we found the corrected values of saturation magnetization $M_{\mathrm{s}}$ and magnetocrystalline anisotropy constant $K_{1}$ presented in Table 1 . The presence of light crystallographic texture can be attributed to the uniaxial pressure applied to the sample during SPS.

\section{TABLE 1 HERE}

\section{DISCUSSION}

Electronic structure and magnetic properties of the equiatomic $\mathrm{Mn}-\mathrm{Al}$ compound were computed using density functional techniques (LMTO, FLAPW) in a number of works. The magnetocrystalline anisotropy energy of the $\tau$ phase depends on its $c / a$ axial ratio so that a tetragonal distortion from a cubic structure stabilizes the system in terms of the Jahn-Teller effect [19]. The ferromagnetic $\mathrm{L}_{0}$ phase may be interpreted to originate from a nonmagnetic B2 phase through a two-step process: an electronic transition in the cubic lattice due to spin polarization, followed by a structural deformation into the tetragonal system [20]. Different first principles calculations give similar values for the magnetocrystalline anisotropy constant: $1.5 \mathrm{MJ} \cdot \mathrm{m}^{-3}$ [19], $1.525 \mathrm{MJ} \cdot \mathrm{m}^{-3}$ [21]. The saturation magnetization (assuming a density of $5008 \mathrm{~kg} \cdot \mathrm{m}^{-3}$ ) is obtained as $0.806 \mathrm{MA} \cdot \mathrm{m}^{-1}$ [21].

Magnetic properties of polycrystalline $\mathrm{Mn}-\mathrm{Al}$ and $\mathrm{Mn}-\mathrm{Al}-\mathrm{C}$ alloys within the $\tau$-phase existence domain were experimentally studied using the singular point detection technique by Pareti et al. [22]. It was confirmed that uniaxial magnetocrystalline anisotropy of this material is well described with only a second-order parameter $K_{1}$. The anisotropy field $H_{\mathrm{a}}$ at room temperature increases with increasing $\mathrm{Mn}$ content and decreases with increasing $\mathrm{C}$ content, the variation being from $3.1 \mathrm{MA} \cdot \mathrm{m}^{-1}$ to $4.2 \mathrm{MA} \cdot \mathrm{m}^{-1}$. It is remarkable that the saturation magnetization $M_{\mathrm{s}}$ exhibits an inverse dependence on the chemical composition, so that the anisotropy constant $K_{1}=\mu_{0} M_{\mathrm{s}} H_{\mathrm{a}} / 2$ remains indeed almost constant in the considered compositional range. From figures in [22] these parameters for $\mathrm{Mn}_{54} \mathrm{Al}_{44} \mathrm{C}_{2}$ alloy can be estimated as follows: $M_{\mathrm{s}}=0.6 \mathrm{MA} \cdot \mathrm{m}^{-1}, K_{1}=1.0 \mathrm{MJ} \cdot \mathrm{m}^{-3}$, in good agreement with our data.

\section{CONCLUSION}

Dense $\mathrm{Mn}$-Al-C permanent magnets have been produced from rapidly solidified alloys by spark plasma sintering 
without additional annealing. The samples have been magnetically characterized in a field sufficient to saturate this material. The ahysteretic parts of magnetization loops were analyzed within a model for the approach to saturation which takes into account possible crystallographic texture. The measured magnetocrystalline anisotropy energy is close to the available predictions of the density functional theory (in $T \rightarrow 0 \mathrm{~K}$ limit) and consistent with other experimental studies. For many materials the observed coercivity amounts to $\sim 10 \%$ of the anisotropy field. Isotropic Mn-Al-C magnets have not yet attained this level.

\section{REFERENCES}

[1] H. Kono, "On the ferromagnetic phase in manganese-aluminum system," J. Phys. Soc. Jpn., vol. 13, pp. 1444-1451, Dec. 1958.

[2] A. J. J. Koch, P. Hokkeling, M. G. v. d. Steeg, and K. J. de Vos, "New material for permanent magnets on a base of Mn and Al," J. Appl. Phys., vol. 31, pp. 75S-77S, May 1960

[3] J. M. D. Coey, "Permanent magnets: Plugging the gap," Scr. Mater., vol. 67, pp. 524-529, Sep. 2012.

[4] J. M. D. Coey, "New permanent magnets; manganese compounds," $J$. Phys.: Condens. Matter, vol. 26, 064211, Feb. 2014.

[5] M. J. Kramer, R. W. McCallum, I. A. Anderson, and S. Constantinides, "Prospects for non-rare earth permanent magnets for traction motors and generators," JOM, vol. 64, pp. 752-763, Jul. 2012.

[6] T. Ohtani, N. Kato, S. Kojima, K. Kojima, Y. Sakamoto, I. Konno, M. Tsukahara, and T. Kubo, "Magnetic properties of Mn-Al-C permanent magnet alloys," IEEE Trans. Magn., vol. 13, pp. 1328-1330, Sep. 1977.

[7] J. M. K. Wiezorek, A. K. Kulovits, C. Yanar, and W. A. Soffa, "Grain boundary mediated displacive-diffusional formation of $\tau$-phase MnAl," Metall. Mater. Trans. A, vol. 42, pp. 594-604, Mar. 2011.

[8] Y. Sakka, M. Nakamura, and K. Hoshimoto, "Rapid quenching and properties of hard magnetic materials in $\mathrm{MnAl}-\mathrm{X}(\mathrm{X}=\mathrm{Ti}, \mathrm{Cu}, \mathrm{Ni}, \mathrm{C}, \mathrm{B})$ systems," J. Mater. Sci., vol. 24, pp. 4331-4338, Dec. 1989.

[9] E. Fazakas, L. K. Varga, and F. Mazaleyrat, "Preparation of nanocrystalline $\mathrm{Mn}-\mathrm{Al}-\mathrm{C}$ magnets by melt spinning and subsequent heat treatments," J. Alloy. Compd., vol. 434-435, pp. 611-613, May 2007.

[10] Z. W. Liu, C. Chen, Z. G. Zheng, B. H. Tan, and R. V. Ramanujan, "Phase transitions and hard magnetic properties for rapidly solidified MnAl alloys doped with C, B, and rare earth elements," J. Mater. Sci., vol. 47, pp. 2333-2338, Mar. 2012.

[11] A. Chaturvedi, R. Yaqub, and I. Baker, "A comparison of $\tau$-MnAl particulates produced via different routes," J. Phys.: Condens. Matter, vol. 26, 064201, Feb. 2014.

[12] A. E. Berkowitz, J. D. Livingston, and J. L. Walter, "Properties of MnAl-C magnets prepared by spark erosion and other rapid solidification techniques," J. Appl. Phys., vol. 55, pp. 2106-2108, Mar. 1984.

[13] J.-G. Lee, X.-L. Wang, Z.-D. Zhang, and C.-J. Choi, "Effect of mechanical milling and heat treatment on the structure and magnetic properties of gas atomized $\mathrm{Mn}-\mathrm{Al}$ alloy powders," Thin Solid Films, vol. 519, pp. 8312-8316, Sep. 2011.

[14] O. Obi, L. Burns, Y. Chen, T. Fitchorov, S. Kim, K. Hsu, D. Heiman, L. H. Lewis, and V. G. Harris, "Magnetic and structural properties of heattreated high-moment mechanically alloyed MnAlC powders," J. Alloy. Compd., vol. 582, pp. 598-602, Jan. 2014.

[15] Q. Zeng, I. Baker, J. B. Cui, and Z. C. Yan, "Structural and magnetic properties of nanostructured Mn-Al-C magnetic materials," J. Magn. Magn. Mater., vol. 308, pp. 214-226, Jan. 2007.

[16] Z. A. Munir, U. Anselmi-Tamburini, and M. Ohyanagi, "The effect of electric field and pressure on the synthesis and consolidation of materials: A review of the spark plasma sintering method," J. Mater. Sci., vol. 41, pp. 763-777, Feb. 2006.

[17] A. Pasko, M. LoBue, E. Fazakas, L. K. Varga, and F. Mazaleyrat, "Spark plasma sintering of Mn-Al-C hard magnets," J. Phys.: Condens. Matter, vol. 26, 064203, Feb. 2014.

[18] A. Shukla and A. D. Pelton, "Thermodynamic assessment of the Al-Mn and Mg-Al-Mn Systems," J. Phase Equilib. Diffus., vol. 30, pp. 28-39, Feb. 2009.

[19] A. Sakuma, "Electronic structure and magnetocrystalline anisotropy energy of MnAl," J. Phys. Soc. Jpn., vol. 63, pp. 1422-1428, Apr. 1994.
[20] Y. Kurtulus and R. Dronskowski, "Electronic structure, chemical bonding, and spin polarization in ferromagnetic MnAl," J. Solid State Chem., vol. 176, pp. 390-399, Dec. 2003.

[21] J. H. Park, Y. K. Hong, S. Bae, J. J. Lee, J. Jalli, G. S. Abo, N. "Neveu, S. G. Kim, C. J. Choi, and J. G. Lee, "Saturation magnetization and crystalline anisotropy calculations for MnAl permanent magnet," $J$. Appl. Phys., vol. 107, 09A731, May 2010.

[22] L. Pareti, F. Bolzoni, F. Leccabue, and A. E. Ermakov, "Magnetic anisotropy of $\mathrm{MnAl}$ and $\mathrm{MnAlC}$ permanent magnet materials," J. Appl. Phys., vol. 59, pp. 3824-3828, Jun. 1986.

TABLE I

MAGNETIC PARAMETERS FROM APPROACH TO SATURATION

\begin{tabular}{ccc}
\hline \hline$T(\mathrm{~K})$ & $M_{\mathrm{s}}\left(\mathrm{MA} \cdot \mathrm{m}^{-1}\right)$ & $K_{1}\left(\mathrm{MJ} \cdot \mathrm{m}^{-3}\right)$ \\
\hline 4 & 0.68 & 1.7 \\
300 & 0.59 & 1.1 \\
\hline \hline
\end{tabular}

Saturation magnetization $M_{\mathrm{s}}$ and magnetocrystalline anisotropy constant $K_{1}$, corrected for the ferromagnetic phase fraction, at two representative temperatures for the $\mathrm{Mn}_{54} \mathrm{Al}_{44} \mathrm{C}_{2}$ alloy sintered at $923 \mathrm{~K}$. 


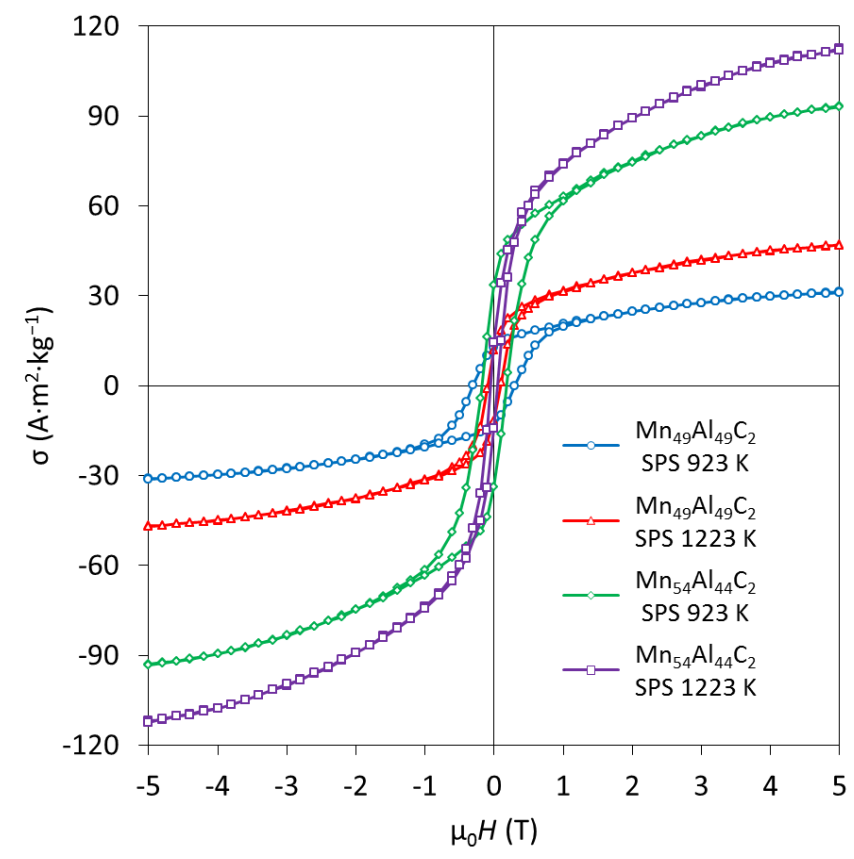

Fig. 1. Magnetic hysteresis loops of the $\mathrm{Mn}_{49} \mathrm{Al}_{49} \mathrm{C}_{2}$ and $\mathrm{Mn}_{54} \mathrm{Al}_{44} \mathrm{C}_{2}$ alloys sintered at different temperatures. The samples with higher coercivity have lower specific moment because of smaller content of the $\tau$-phase.

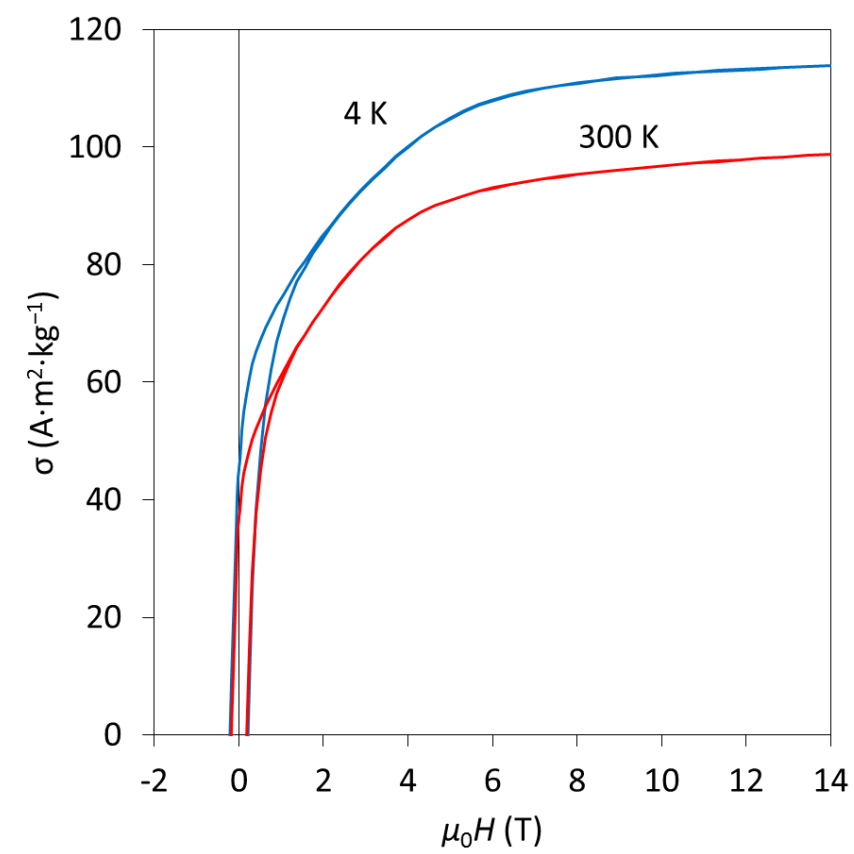

Fig. 3. Magnetic hysteresis loops of the $\mathrm{Mn}_{54} \mathrm{Al}_{44} \mathrm{C}_{2}$ alloy, sintered at $923 \mathrm{~K}$, in a field of up to $14 \mathrm{~T}$ at different temperatures.

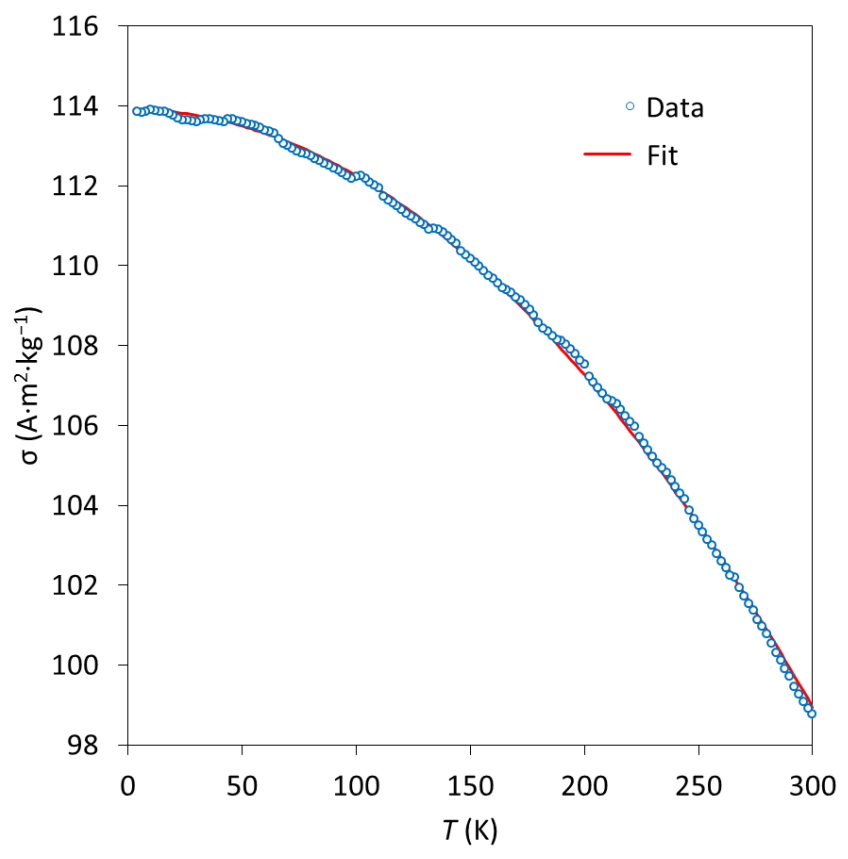

Fig. 2. Specific moment as a function of temperature for the $\mathrm{Mn}_{54} \mathrm{Al}_{44} \mathrm{C}_{2}$ alloy sintered at $923 \mathrm{~K}$. The experimental data follow well a quadratic (without linear term) law.

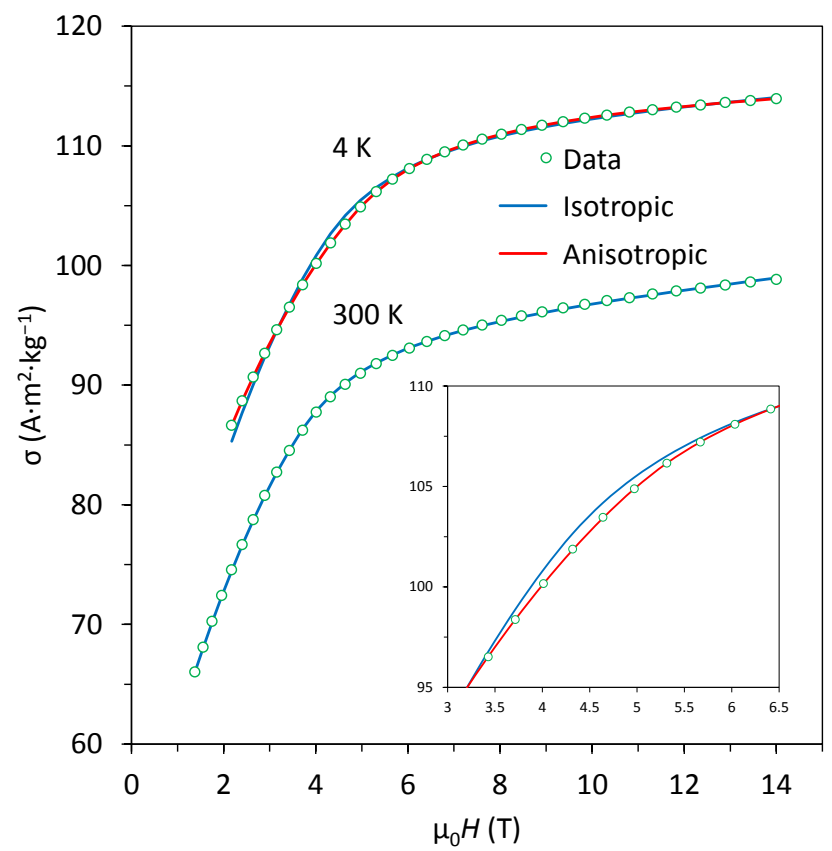

Fig. 4. Ahysteretic parts of magnetization curves for the $\mathrm{Mn}_{54} \mathrm{Al}_{44} \mathrm{C}_{2}$ alloy, sintered at $923 \mathrm{~K}$, at different temperatures. Fitting to isotropic and anisotropic models for the approach to saturation. In the inset a magnified fragment of the $4 \mathrm{~K}$ curve illustrates the difference between the two approximations. 